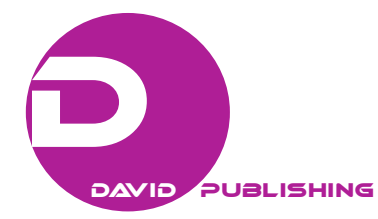

\title{
Statistical and Economic Issues Concerning the Rural Poor; Retrospect and Prospects
}

\begin{abstract}
K.N. Pathak* \& J.S. Tomar**
Decent living based on regular and secured earning is one of the fundamentals of prosperous life. For well-being/upliftment of rural poor some of the basic components required are basic education, productive and decent employment and health care. The amenities of common people`s life do rotate around these. Due to geophysical and cultural diversities prevailing in our country, the nature and dynamics of development in different States has notable variations. Our rural areas have also progressed and changed but they still need a lot to be provided. To ensure a balanced development in our country we need to lay emphasis on upliftment of the rural and marginalized poor. To accomplish this task government is working in this direction. However, it is still felt that concerted efforts are required on the basis of micro level background information. It could be done by addressing some of statistical and economic issues. The notable among them are percentage of surpluses mobilized from labour saving technological change utilized for essential services such as health, sanitation and education to entertainment and cultural activities; variation in acreage from traditional food crop to cash crop; changing trend, of the prices of agricultural inputs vis-à-vis the cost of agricultural output and use of ground water in cultivation; trend of informal credits in relation to rising cost of cultivation; analysis of the dynamics of welfare Schemes regarding employment, healthcare and basic education etc. Inclusive growth was the cardinal principle of 11th Five Year Plan of our country. It was further strengthened in 12th Five Year Plan by prefixing faster and sustainable features to it. Therefore, in order to ensure that this basic objective is being fulfilled; it is necessary that along with policy making there should be in-built components of data collection, monitoring and evaluation.
\end{abstract}

Keywords: Socioeconomic development, MGNREGA, RSBY, SSA, inclusive growth, monitoring and evaluation mechanisms]

In spite of the fact that urbanization is growing in India, a vital chunk of population still inhabits in rural areas. Urban population is yet to touch the half of the country's population. The 2011 census estimates that 68.2 per cent of our population or 833 million people continue to live in rural India. A very large proportion of them are either wholly or significantly dependent on their livelihood on farm activities.

However, we need to have many components to be incorporated in our development programmes for the large and long term benefit of rural community. Out of those some of key issues which need to be given priority over the other when we consider the economic upliftment of rural poor. Ensuring employment to every job seeking person for decent living is one of the basic components of the government policy. But to translate it into reality is certainly an uphill task.

K.N.Pathak* and J.S.Tomar** are working as Joint Adviser in Project Appraisal \& Management Division of Planning Commission and Deputy Director in Central Statistics Office, MoS\&PI respectively. The views expressed in this paper are those of the authors and not of the institution to which they belong. E-Mail for correspondence: jeet.iasri@gmail.com 


\section{Employment and Skill Development}

Till two decades ago the share of agriculture in total employment was nearly $70 \%$ in the Indian economy. The most recent National Sample Survey (2009-10, $66^{\text {th }}$ Round) data shows that this share has declined over time to 53\%. The details of Percentage distribution of Workers (ps+ss) engaged in Agriculture and Non-Agriculture sectors in 2009-10 are given in the following table:

\section{Percentage Distribution of Workers (ps+ss) Engaged in Agriculture and Non-Agriculture Sectors}

\begin{tabular}{|c|c|c|}
\hline Category of Workers & Agriculture & Non-Agriculture \\
\hline \multicolumn{3}{|c|}{ All India } \\
\hline Male & 47.2 & 52.8 \\
\hline Female & 68.7 & 31.3 \\
\hline Persons & 53.2 & 46.8 \\
\hline \multicolumn{3}{|c|}{ Rural } \\
\hline Male & 62.9 & 37.1 \\
\hline Female & 79.3 & 20.7 \\
\hline Persons & 68.0 & 32.0 \\
\hline \multicolumn{3}{|c|}{ Urban } \\
\hline Male & 05.9 & 94.1 \\
\hline Female & 13.8 & 86.2 \\
\hline Persons & 07.5 & 92.5 \\
\hline
\end{tabular}

It may be noted that between these two sectors of activities the agriculture sector accounted for more than $50 \%$ i.e. $53.2 \%$ of workers (ps+ss) and in this sector, the distribution of workers is more skewed in favour of the rural areas with nearly $68 \%$ of workers being engaged in the agriculture activities and merely $7.5 \%$ in urban areas. Besides the rural-urban differences in the distribution of workers, the gender-wise differences are also quite significant -in rural areas, nearly $79.3 \%$ females engaged in agriculture compared to $62.0 \%$ males and in the urban areas nearly $13.8 \%$ were engaged in agriculture compared to only $5.9 \%$ among males. A higher proportion of female workforce in agriculture as compared to their male counterpart shows dominance of female workers in the agriculture sector and particularly in the rural areas this is more dominant.

But given the fact that $53 \%$ of the Indian workforce is producing barely $15 \%$ of the Gross Domestic Product (GDP), the decline in the share of agriculture in the total employment is nowhere close to fast enough and it is still high. Therefore, increasing employment outside of agriculture i.e. transition of labour force from agriculture sector to non-agriculture sector is one of the prime objectives of policy makers.

However, in an economy which is suffering from $6.6 \%$ unemployment (2009-10) by the current daily status (CDS) concept this is very challenging/ difficult task. Particularly shifting the rural female workers is more difficult, because in rural areas employment avenues are very limited and if they shifts (migrates) to urban areas, they may be able to find casual works in informal sector only. This kind of work is still not such as to provide employment security or income security or social security. In brief, this will not fulfill the condition of decent and productive employment (which is one of the objectives of the Twelfth Five- Year Plan, in the context of employment generation) and they will encounter many problems of urbanization as well.

Thus, most suited option is to convert/upgrade the skills of unskilled labours in agriculture and allied sectors to skilled one through skill development mission. However, recent data has shown that our education 
system and vocational training programmes have not been able to provide the adequate size of skilled manpower. As per the NSSO 61 ${ }^{\text {st }}$ Round (2004-05) survey, among the persons of age 15-29 years, only 2 per cent are reported to have received formal vocational training and another 8 per cent have received non-formal vocational training. This indicates that very few young persons with formal vocational training enter the workforce. This proportion of trained youth is one of the lowest in the world. Thus, one of the key challenges before the Government is to raise the proportion of trained youth significantly to enable India to emerge as global leader.

Keeping the above situation in view, the Government has put in place a Coordinated Action on Skill Development in May, 2008 with a three-tier institutional structure, viz. Prime Minister's National Council on Skill Development for overall policy direction, mid-course direction supported by National Skill Development Coordination Board chaired by Deputy Chairman, Planning Commission and National Skill Development Corporation under the Ministry of Finance.

The main emphasis by the Government is on institution based skill development through polytechnics, ITIs and Vocational Training Centers, Apprenticeship Training, Training for Self Employment and Entrepreneurial Ventures, addressing the training requirements of various stakeholders.

Third Session of Standing Labour Committee organized by Ministry of Labour \& Employment, Govt. of India in February, 2009, focused on skill deficit mapping. The National Policy on Skill Development approved by the Union Cabinet on $23^{\text {rd }}$ February, 2009 envisages setting up of Labour Market Information Systems and Human Resource Planning for the reliable and realistic assessment of economic trends and labour market needs. The policy mandates skilling of 500 million people by the year 2022. The policy also included the provision of setting up of a National Vocational Qualification Framework and quality assurance mechanism. For skill demand analysis and curriculum development, Government has set up a National Skill Development Corporation (NSDC) with responsibility to constitute Sector Skill Councils which include identification of skill gaps, preparation of skill development plans, determining skills/ competency standards and qualifications. Through the convergence approach the Government envisages to facilitate creation of pooled skilled personnel with adequate skills in line with employment requirement across the entire economy with surpluses to cater to the skill deficits in other ageing economies.

\section{Indian Agriculture}

While analysing the quality of life of rural people in relation to agriculture we need to take in account demand - supply aspect, impact of liberalization and farm technology etc. It has been felt that in global markets, demand factors have played a very little role in causing price increases and the dominant effect has been in changed conditions of supply. These include the short run effects of diversion of both acreage/land use/cropping pattern and use of food crop outputs for other purposes like bio-fuel production etc. There are also some medium term factors which need to be taken into account such as rising cost of inputs, falling productivity because of soil depletion, excessive use of ground water in cultivation, inadequate public investment in agricultural research and extension and the impact of climate change, which led to shifting of seasons, desertification and loss of cultivable land that has affected harvests in different ways.

Greater trade openness and market orientation of farmers have led to shifts in acreage from traditional food crops that were typically better suited to the ecological conditions, the knowledge and resources of farmers, to cash crops that have increasingly relied on purchased inputs. There is also a feeling that the cost of 
cultivation have been further increased in most developing countries by the growing difficulties that farmers have in accessing institutional credit because financial liberalization have moved away from the policies of direct credit and provided other more profitable (if less productive) opportunities for financial investment. Hence, many farmers, according to them, are forced to opt for much more expensive informal credit networks that have added to their cost.

It is also felt that reliance on capital-intensive farming technology in labour-abundant economies is not only inconsistent with factor endowments, but it also generates income inequality by augmenting property incomes (which accrue to landowners and speculators) and reducing the income share of the rural masses. Thus, agricultural technology ought to aim at producing inexpensive farm implements and equipment that can be widely used on small farms and operated by farmers with limited purchasing power. In the words of agricultural economists, farming technology must be 'unimodal', that is to say, 'aimed at the progressive modernization of the bulk of the nation's cultivators, as contrasted to a "bimodal" crash modernization effort concentrated upon a small subsector of large-scale mechanized farms'.

Even the economists who favour labour oriented economic development by and large finally agree upon the view that focus should not be on preventing labour - saving technological progress from occurring but rather on ensuring that surpluses from such activities are mobilized within (directly through taxation or indirectly through provisions of incentives) and transfer to demand other activities that employ more labour, even as they improve the quality of life. This implies that surpluses generated from 'productive activities' could be used in a proliferation of service activities in everything from the provision of essential services like health, sanitation and education to entertainment and cultural activities.

The following statistical and economic issues emerge from the above elaboration:-

(1) To examine the nature and quantum of short and medium term effects on supply.

(2) To analyse the trend of public investment in agriculture and agricultural research and variation in acreage from traditional food crop to cash crop, particularly in the last two decades.

(3) Collecting and analysing the data regarding the use of ground water in cultivation, measures taken for preserving and regenerating it as well as soil and land quality.

(4) Analysing the changing trend of the prices of agricultural inputs vis-à-vis agricultural outputs and informal credits.

(5) Examining the nature and quantum of low cost technology, which has been considered by small farm holders and the percentage of success in case of innovations acquired over several decades of technical assistance programme.

(6) To examine the nature and extent of surpluses mobilized from labour saving technological change and percentage thereof utilized for essential services like health, sanitation and education to entertainment and cultural activities.

\section{Welfare Measure}

The statistical and economic issues involved in economic upliftment of the people of our country, inter-alia, relate to some key welfare or redistributive measures such as employment schemes, incentivized cash transfers to particular social groups, social protection like health benefits, old age pension, widow pension, unemployment benefits etc. These can become important macro-economic stabilizers by providing counter-cyclical buffers. 


\section{Mahatma Gandhi National Rural Employment Guarantee Act (MGNREGA):}

The main example to be considered in this regards could be that of Mahatma Gandhi National Employment Guarantee Act (MGNREGA). Over the past five years, it has provided nearly 9,000 million person days of work at a total expenditure of more than Rs. 110,000 crore. Thus, this scheme not only provides a higher number of days for employment for amount spent than any previous employment programme in India but has also been an important means of injecting purchasing power into a depressed rural economy and limiting the adverse effects of economic down turn on rural effective demand. MGNREGA has been highly inclusive, as is evident from the fact that the share of Scheduled Castes/Scheduled Tribes (SC/ST) families amongst beneficiaries has ranged between 51-56 per cent and 41-50 percent of workers have been women. It has also promoted financial inclusion since over 100 million bank/post office accounts have been opened for the poorest segment of our population who comprise of MGNREGA workforce.

MGNREGA is perhaps the most ambitious anti-poverty scheme launched anywhere in the world. However, this strategic measure of the Government is confronting many issues which need to be addressed for ensuring its effective implementation such as poor planning and administrative skill, quality of work, work demand not correctly represented, delays in measurements, valuations and payments, lack of social audit and evaluation etc.

\section{Rashtriya Swasthya Bima Yojana (RSBY):}

National health accounts data reveals that the Government sector (centre, state and local) together accounted for only $20 \%$ of all health expenditures and $78 \%$ took the form of out-of-pocket payments - one of the highest percentages in the world. Despite a government owned free health care delivery chain, $64 \%$ of the poorest population in India is indebted every year to pay for the medical care they need. $85 \%$ of the Indian workforce working in the informal sector do not have any kind of insurance and lack access to effective social protection schemes. Taking due cognizance of that the Government launched Rashtriya Swasthya BimaYojana (RSBY) in 2008.In less than 3 years more than a third of India's Below Poverty Line (BPL) families have been enrolled under the RSBY.

The objective of RSBY is to provide protection to BPL households from financial liabilities arising out of health shocks that involve hospitalization. Beneficiaries under RSBY are entitled to hospitalization coverage up to Rs. 30,000/- for most of the diseases that require hospitalization. Government has even fixed the package rates for the hospitals for a large number of interventions. Pre-existing conditions are covered from day one and there is no age limit. Coverage extends to five members of the family which includes the head of household, spouse and up to three dependents. Beneficiaries need to pay only Rs. 30/- as registration fee while Central and State Government pay the premium to the insurer selected by the State Government on the basis of a competitive bidding.

It is likely that this health insurance scheme in our country, where the expenditure upto Rs.30,000/- per family of five members is borne by government through insurance agencies would certainly contribute significantly for releasing more disposable income to households, thereby boosting their consumption and adding to domestic demand for this segment of population.

As the scheme covers a vast segment of workers in the unorganized sectors who are largely spread in rural areas also, an economic analysis is required through the statistical data. The number of cases examined, the number of cases treated for various diseases and the coverage of families may be analyzed in order to have a perception at the national level. This scheme is a landmark scheme which is being considered for emulation by 
various countries such as Bangladesh, Pakistan, Nepal and Iraq.

Release of matching fund from State Governments as well as Central Government in the form of premium to insurance companies and disbursal to different hospitals through insurance companies are some of the important data to be gathered and analyzed to assess the success of a social insurance scheme like RSBY at all India level. The other important aspect to be studied from economic angle in case of the beneficiaries of RSBY scheme is the emerging trend of consumption by them as a result of the benefit accrued through the scheme.

\section{Universal Elementary Education (UEE):}

Education is the single most important instrument for social and economic transformation. A well educated population adequately equipped with knowledge and skill is not only essential to support economic growth but is also a precondition for growth to be inclusive.

Sarva Shiksha Abhiyan(SSA) since its inception in 2001-02 as the main vehicle for providing elementary education to all children in the 6-14 years age-group, has made considerable progress in universalization of elementary education. However, with the Right to Education (RTE) Act, 2009 having come into effect from April 2010, it is now a fundamental right of all children to demand eight years of quality elementary education.

Despite improvement in access of children to elementary education their retention and improving their learning outcomes are the two main concerns. The other issues related to this are teacher-pupil ratio and provision of infrastructure facilities to ensure quality of education. With a view to ensure that rural children are benefitted in terms of educational development on all the parameters of education; it is necessary that a proper monitoring and evaluation mechanism is followed rigorously.

\section{Data Collection: Agency, Periodicity and Response}

It is observed that for collecting data for various sectors, there are different agencies having different periodicity of data collection and have different approach and mechanism. What is required, therefore, is that there should be uniformity of approach and mechanism. Moreover, if data collection is handled by one central agency it would ensure uniformity, reliability as well as timeliness.

Employment -unemployment is a pivotal issue of development. By addressing this aspect Government could cater to overall development to a large extent. Only by having a clear vision of the length and breadth of employment - unemployment in the country the planners and policy maker can be expected to take appropriate corrective measures. Beginning from the 9th round (May-September, 1955) the National Sample Survey Office (NSSO) has conducted a number of quinquennial surveys on employment and unemployment to assess the volume and structure of employment and unemployment. The findings of those survey results could be used for formulating governmen's policy on creation of employment opportunities with special focus on rural India.

The longer time frame (about five years) between the two quinquennial rounds appears to be an obstacle in the planning process. Various agencies of the Government dealing with employment and development programmes need updated data in order to ensure that their programmes /schemes are commensurate with the available labour force. The requirement of current position of employment-unemployment data through annual surveys is an issue of critical contemporary significance keeping in view the context of environment of fluctuating growth and also for fully utilizing India’s demographic dividend.

The annual data on employment - unemployment is required primarily in view of the fact that the quinquennial surveys conducted by NSSO capture the data of a particular year preceding the survey. Such 
survey does not capture the data of the period prior to that, or the volatility in the market such as recession or slump occurring during the inter-regnum period. Therefore; to deal with the crises occurring in between the two quinquennial surveys, it is necessary to have updated annual data on employment and unemployment.

In addition to the issue of uniformity and timeliness of data collection the other important aspect is capability of respondent and cooperation received from them. The two main problems faced by the data collectors during different surveys are lack of capabilities of a large number of respondents and cooperation extended by them to the data collector.

Through an analysis of recent Employment-Unemployment survey data it has been observed that about $20 \%$ respondents are either not capable of answering the question or do not cooperate with the data collector. It reflects that the data which is being collected through the large scale national surveys is also suffering from such a fallacy of having $20 \%$ inappropriate information. There are numerous reasons for this which needs to be addressed by planners/ policy makers.

Government has been focusing on development for long. Various steps have been taken to ensure development through optimal utilization of resources. Inclusive growth was the cardinal principle of 11th Five Year Plan of our country. It has further been strengthened in 12th Five Year Plan by prefixing faster and sustainable features to it. To ensure that this basic objective is being achieved; it is necessary that along with policy making there should be in-built components of data collection, monitoring and evaluation. This could be made better possible by addressing the key issues highlighted in this paper.

\section{Reference:}

Draft Plan Document, Twelfth Five Year Plan (2012-117), Planning Commission, Govt. of India.

Employment and Unemployment Situation in India 2004-05, NSS 61 ${ }^{\text {st }}$ Round (July 2004 - June 2005), National Sample Survey

Office, Ministry of Statistics and Programme Implementation, Govt. of India.

Eleventh Five Year Plan (2007-12), Planning Commission, Government of India.

Key Indicators of Employment \& Unemployment in India - 2009-10, NSS 66 ${ }^{\text {th }}$ Round (July 2009 - June 2010), National Sample

Survey Office, Ministry of Statistics and Programme Implementation, Govt. of India.

Provisional Population Totals, Census of India 2011, O/o RGI, Govt. of India. 